Whether a flaneur or an angel of history, the artist in Iza Caparas sees the fulfillment of human existence, where the naturalism of man and the humanism of nature are one and the same.

Gallery Nine presents "URBAN LIFE," a solo exhibition of paintings by Iza Caparas on May 10-20, 2011. Gallery Nine is located at 4th Floor, Building A, SM Megamall, Mandaluyong City, with tel. no. 910-8016.

\title{
Care Divas by PETA
}

\author{
Walter O. Ang
}

Philippine Educational Theater Association's Care Divas, a musical that revolves around the friendship/s between Filipino contract caregivers in intifada-infested Israel, wraps heavy themes of displacement, frustration and loss with song-and-dance. And with sauciness, thanks to the five protagonists who moonlight as drag queens.

These relationships are anchored by the story of Chelsea (played by Melvin Lee) as she navigates her own relationships: with her "care diva" friends, with her employer/patient and, of course, with her love interest. Two other care divas, Kayla (Ricci Chan alternating with Jerald Napoles) and Shai (Vince De Jesus) provide somewhat major subplots, while Thalia (Jason Barcial, Dudz Teraña) and Jonee (Buddy Caramat, Phil Noble), are mostly for comic relief.

On the whole breezy and fun, the musical alternates light scenes with heavier, dramatic episodes, interspersed throughout with music and lyrics by De Jesus and choreography by Carlon Matobato. It ends with, expectedly, a big glamorous production number, feathers and all. Some staging and narrative choices, however, create runs in this production's stockings. 


\section{Identity}

In this story by playwright Liza Magtoto, we are shown the lives of men-whoidentify-as-women, who are strange strangers in a strange land. Director Maribel Legarda has one actor (Paul Holme) portraying all the Israeli patients of most of the care divas and a few other actors doing double roles of Israeli characters.

It's theatrical and fun; we get to see actors switching several characters on and off. It also serves to say that this story is not so much about "them"/"the other" (the Israeli employers/patients) than it is about the care divas, who, in turn, are the ones regarded by the majority as

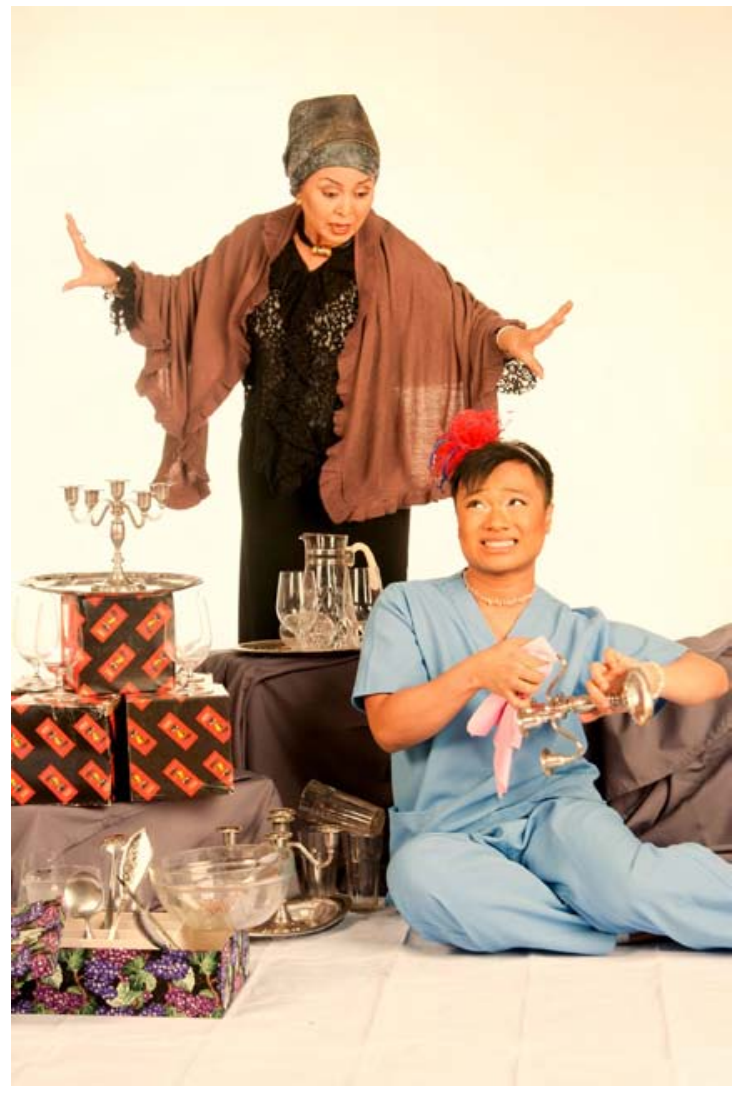
"them"/"the other." Even if these care divas use gender-bending make-up and costume, they have more solid and fully formed identities than "the other" characters around them.

One has to wonder, then, what the production is trying to say by having only one Caucasian actor in the cast and relegating all other non-Filipino roles to Filipino actors. Obviously, it's not easy to cast Caucasians in Manila, but the color-blind-save-for-one-actor set-up seems a little off-kilter visually, especially when, in this world that Magtoto presents, notions of appearanceas-part-of-identity (and the illusions that are related to and a result of it) is such an integral component. 


\section{Demonizing Gender}

Contingent to the issue of identity, in this case, are gender and sexuality. Magtoto refreshingly places the characters right in the middle of the action, without stereotypical, melodramatic, and trite back stories of attempting to explain/ justify the hows and whys of the homosexuality and/or the cross-dressing.

Surprisingly, however, given the self-identification of the lead characters as women, the text harbors a misogynistic streak. The care divas' sole female friend Nonah (Angeli Bayani), is, at one point, considered a traitor to their cause. And then there are the mothers: Israeli mother and Shai's off-stage voice-over mother are both demonized as the enemy.

The men, in general, are there in a heroic capacity: the supportive boyfriend, the understanding patient, the love interest. The care divas are brave enough to cross oceans to find work and to cross-dress in this far-away city, but perhaps deep down, beneath the glitter, they are still simply barrio lasses who dream of the macho (and if we want to split hairs: also, feudal/upper class and foreign/colonial) knight to come and save them?

\section{Slow, Unwieldy}

Legarda's direction is even-handed, although the pacing is slow. The material doesn't seem like it should take more than two hours to unfold. The first act scenes seem to start in fits, though the interweaving expository monologues introducing the care divas as they pass on their patient/s to one another is clever.

Some scenes, like whenever the care divas are in their friend Nonah's flat, seem to be written and staged in the manner of the slow, lingering starts for TV or film scenes; you can almost feel (and have to wait for) the invisible camera panning for an establishing shot before someone starts talking.

The sculptural set design by Leo Abaya is unwieldy. Though it has a crafty carved-out seating area that doubles as a patient's bathtub, the downstage cross-inclined ramps could have been omitted to concentrate the action onto a more focused space. 


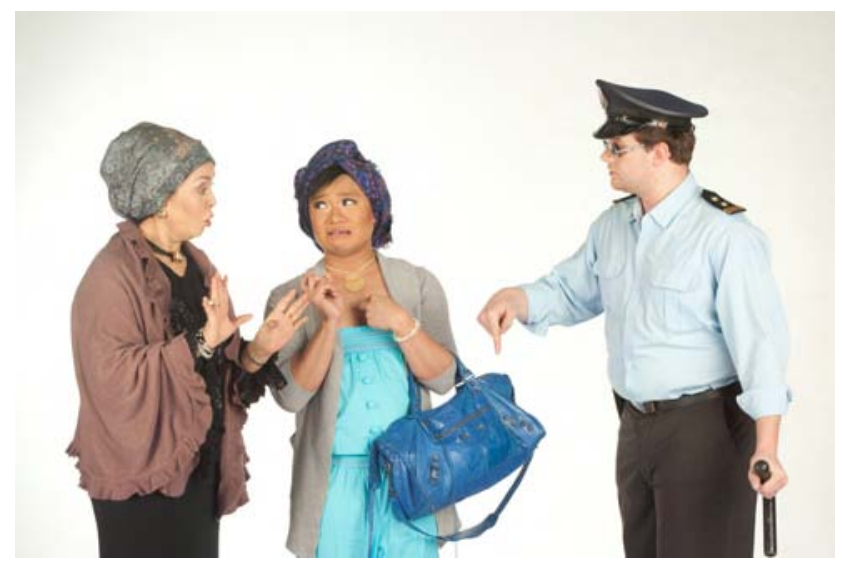

The unwieldiness is highlighted by Legarda's blocking a majority of the scenes to the sides and downstage. While this can be construed as a symbolic use of space to bring our attention to the marginalized existence of the care divas, it also leaves us feeling puzzled as to why the center area seems left unused for large portions of the performance.

And while drag performances naturally involve superfluous showboating, perhaps that's where it should stay, and not conveyed via descending lampposts from the rafters, even if they can be construed as metaphors for phallic symbols piercing into the care divas' lives.

\section{Awkward}

Magtoto's text leans on recurring awkward endings to problems, as a marker for the way the characters need to bank on acceptance and resignation as they struggle through their fleeting, unstable, risk-filled, oppressive world.

Shai's backstory showcasing her strained relationship with her mother is left unresolved; she simply leaves for work in another country. Adding to the awkwardness is the way the mother is never seen on-stage, and instead is merely channeled by Shai's patient and by the care divas-as-Greek-chorusas-mother-as-a-monster. 
The device used to present this absent character is good for laughs, but doesn't really seem to serve a point. It feels trite in that it's used to explain some of Shai's caustic personality; but why is she the only character whose personality has to be explained? And why is it explained in this mother-as-monster manner-a deviation from the mostly "realistic" approach for everything else?

Kayla's subplot ends when she is deported. The other care divas are unable to help her and they move on. Even when they are double-crossed by the bar owner who hires them, the care divas march on.

When Chelsea discovers a considerably large kink in her potential love relationship (a wonderful twist that further layers and skewers notions of truth / identity / costume / appearance / deceit), she pushes forward.

\section{Kindness}

Magtoto's use of awkward endings and numerous subplots create a sense of unease. There are points in the production when one wants to ask "Whose story is this really?" But perhaps her point is to reinforce the one other trait

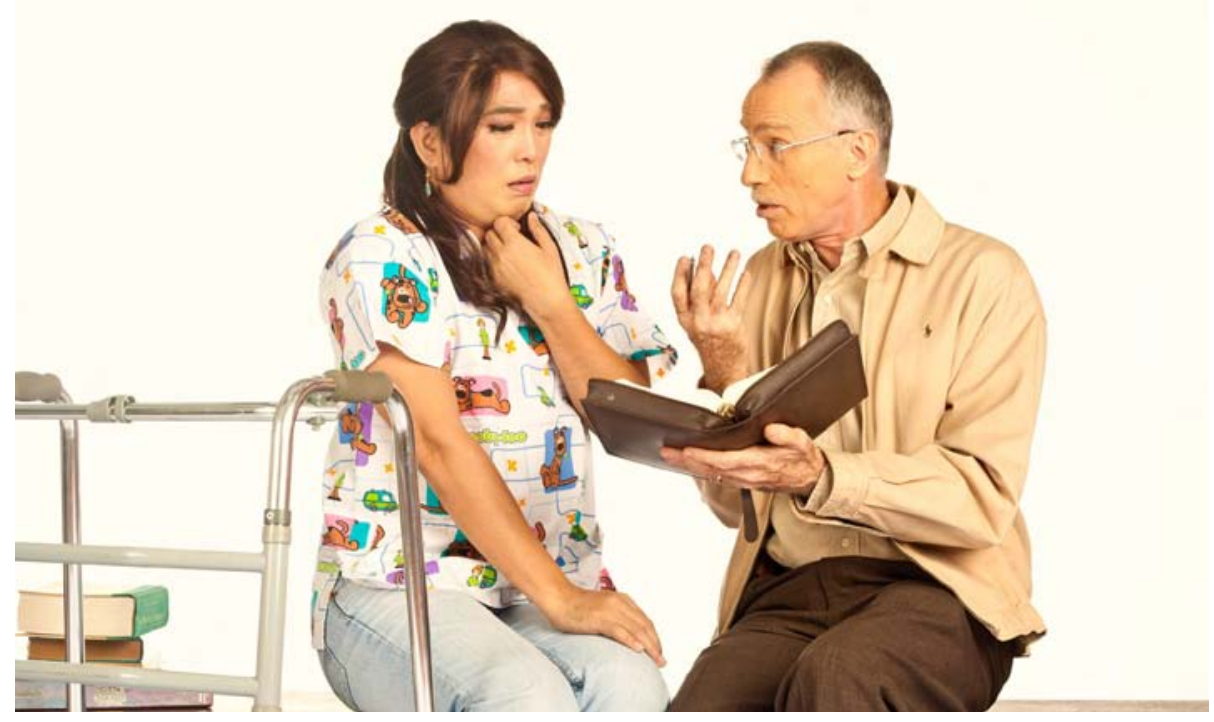


the characters bank on: hope. That their minds and hearts instinctively grasp at all and any chance at it, real or illusory.

At least there is hope that stems from the kindness of strangers (Israeli or otherwise) and friends (Filipinos or otherwise) in the strange land. And the care divas respond in kind.

The care divas sing about being bad girls, use snarky put-down punchlines with each other, and kvetch about their employers and their jobs and their lives, but Magtoto's dialogue and De Jesus' songs allow audiences to see that these divas really do care: about each other, the people they have to care for, and the people they want to care for.

Walter O. Ang has contributed theater-related feature articles and reviews to the Philippine Daily Inquirer and a few other publications (print and online). He has taken workshops in stage management, set design and lighting design with various groups such as Gantimpala Theater Foundation, the Cultural Center of the Philippines, and Sinag Arts Foundation. He was a guest artist for Ballet Philippines' national tour of Shoes++ in 2002, and was a fellow in 2009 of the University of Santo Tomas Varsitarian-J. Elizalde Navarro National Writing Workshop on Criticism for the Arts and Humanities. He prepared a paper on "From stage to page: re/viewing the views of reviewers" for the National Commission for Culture and the Arts' Tanghalan! National Conference on Philippine Theater Aesthetic 2009. Recent production credits include assistant production management and dramaturgy for the University of the Philippines Los Baños Centennial Performances Committee's 2010 staging of Tegenif, a Tagalog translation/adaptation of August Strindberg's A Dream Play.

Gary C. Devilles teaches Philippine Literature and Popular Culture in Ateneo de Manila University. His research interests include Urban Studies, Marxism, and Arts Studies. He contributes art reviews to the Philippine Daily Inquirer, Manila Times, Metro and Muse.

Nonon G. Padilla was the founding artistic director of Tanghalang Pilipino, which brought original Filipino productions to Japan and France. He is a recognized print maker. 